\title{
Lessons from the Social Psychology of Evolution Warfare: Good Science Alone is not Enough
}

\author{
Raymond Arthur Eve • Susan Carol Losh • \\ Brandon Nzekwe
}

Published online: 26 May 2010

(C) Springer Science+Business Media, LLC 2010

\begin{abstract}
American student acceptance of evolution is far from uniform, even when students experience instruction in the relevant scientific methods and data. But, excellent science teaching alone cannot be expected always to lead to rejecting creationism. Powerful psychological, social, and political forces are at work as well as pure pedagogy, and such forces are often implicated in the failure of students to accept evolution, especially human evolution. These forces are often sufficiently powerful to defeat even attempts to teach evolution that use the most effective science education methods. We end by urging increased activism on behalf of evolution education.
\end{abstract}

Keywords Creationism · Intelligent design · Teaching · Pedagogy

\section{Introduction}

For modern life scientists, the war between evolution and creationism is long over, with evolution the clear

\footnotetext{
R. A. Eve $(\bowtie)$

Department of Sociology and Anthropology,

The University of Texas at Arlington,

Box 19599 UTA, Arlington, TX, USA

e-mail: eve@uta.edu

S. C. Losh • B. Nzekwe

Department of Educational Psychology and Learning Systems,

Florida State University,

Tallahassee, FL 32306-4453, USA
}

victor. ${ }^{1}$ Yet the war continues to rage wherever evolution is publicly expounded and discussed in the United States - in museums and zoos, in the media and onscreen, across the Internet, and, most crucially, in the public school systems. In this discussion of the social and behavioral science aspects of the creationism/evolution controversy, we begin by documenting the popularity of US antievolution attitudes as revealed by polls. Then, we describe the social factors that underpin them. The data indicate, perhaps surprisingly, that simply providing students with an excellent biology education is insufficient to dispel supernatural explanations of the history of life. Finally, we offer suggestions for the classroom and beyond, to help to fight the battles better and, ultimately, to prevent them.

\section{Stasis in Public Opinion on Evolution}

Biological evolution is far from the only subject the general public deems controversial. For example, other current

\footnotetext{
${ }^{1}$ By creationism we refer to the rejection of evolutionary accounts of the history of life in favor of accounts involving creation by a supernatural entity; see Pennock (2003). Note that on this definition, merely believing that God created is not enough to be a creationist; it is necessary also to reject evolution. The most popular form of creationism in the United States presently, often termed "young-earth" creationism, holds that a divine being directly created the world and the different kinds of organisms over a period of a few days less than 10,000 years ago; there are also various forms of "old-earth" creationism. In the United States, creationism is usually based on a particular reading of the Christian Bible, although there are forms of creationism in the United States and elsewhere with roots in different religious traditions. Intelligent design, despite attempts of its proponents to portray it otherwise, seems to be primarily a marketing strategy for creationism rather than a distinct form of creationism itself; see Forrest and Gross (2007).
} 
disputes rage over global warming or conjectured links between childhood vaccines and autism (Greenfield 2010; Specter 2009). What these quarrels share is that they exist among members of the lay public, but generally not among scientists. To date, evolution has generated the greatest continuing US public debate over a scientific subject, although it is a subject on which modern life scientists overwhelmingly agree. As a result, the creationism/evolution controversy invites attention not only to science education but as well to many social, psychological, and cultural factors.

Since at least the 1980s, American public opinion polls about evolution and creationism have been remarkably stable (although there is room to disagree about what they in fact indicate; see Bishop 2006). In 1982, the Gallup organization reported that 44 percent of a nationally representative survey of US residents agreed, "God created man pretty much in his present form within the past 10,000 years" (Pennock 2002). This fraction has changed little since. Figure 1 shows Gallup national samples (typically with a minimum of 1,000 respondents each) from 1982 to 2007 (Newport 2007). The top line corresponds to the creationist opinion ${ }^{2}$; the middle line to the opinion that God guided the development of human beings over millions of years; and the bottom line to the opinion that human beings developed over millions of years but "God had no part in this process."

In a national survey sponsored by the American Association for the Advancement of Science, the Pew Research Center for the People and the Press (2009) documented substantial disparities between samples of more than 2,500 scientists and 2,001 American adults on the idea "that evolution is the result of natural processes such as natural selection," which $87 \%$ of scientists but only $32 \%$ of the public endorsed. Another $22 \%$ of the public attributed human evolution to guidance by a "supreme being" and 31\% asserted that humans have existed in their present form "since the beginning of time." Most (57\%) white evangelical Protestants believed that humans have existed in their present form since time began, a view shared by $41 \%$ of black Protestants, $27 \%$ of Catholics, and $23 \%$ of white "Mainline" Protestants, but by only $11 \%$ of those with no religious affiliation. Forty-five percent of baccalaureates accepted "natural evolution" compared with $31 \%$ of those with some college but only $26 \%$ of those with at most a high school degree.

How do US adults compare to other nations? Figure 2, incorporating data from more than 10,000 adults, shows

\footnotetext{
${ }^{2}$ Not the young-earth creationist view as such, since this option is probably also favored by old-earth creationists too, who acknowledge that the earth is billions of years old but who think that Adam and Eve lived on the order of 10,000 years - perhaps as long as 50,000 or 100,000 years - ago.
}

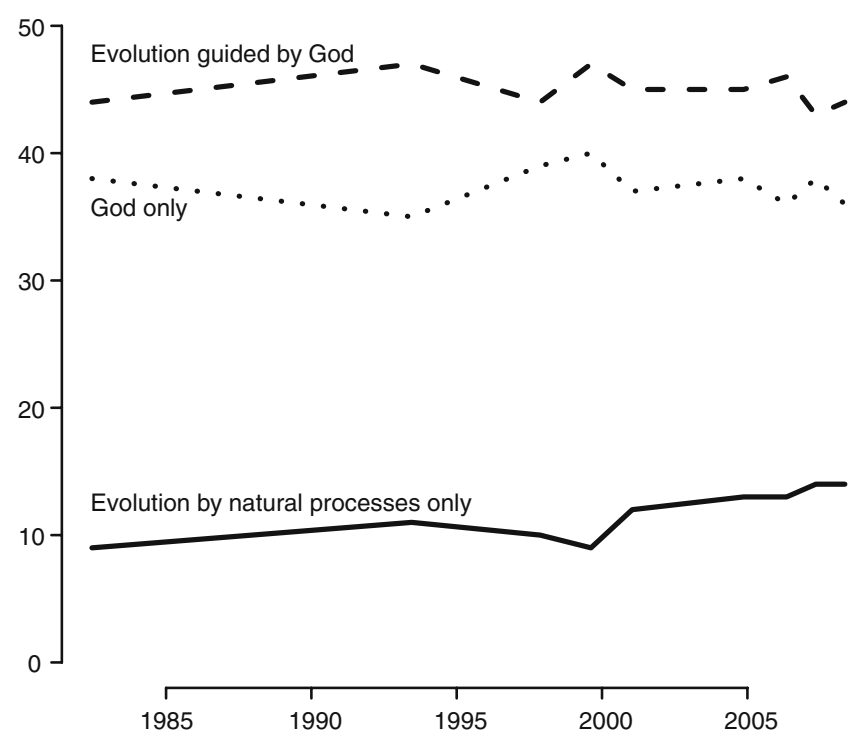

Fig. 1 Responses from Gallup polls on evolution, 1982-2007. (Data from Newport 2007)

that the United States accepts evolution less than many other developed nations (Rogers 2009), although some other countries, less economically developed and/or Muslim, have even lower rates of acceptance.

Miller et al. (2006) collated 20 years of data on views on evolution from 32 European countries, Japan, and the United States. Only Turkey manifested more rejection of evolution than the United States. For a discussion of the etiology and distribution of creationism in international context, see Coleman and Carlin (2004) on Englishspeaking countries and Branch (2008).

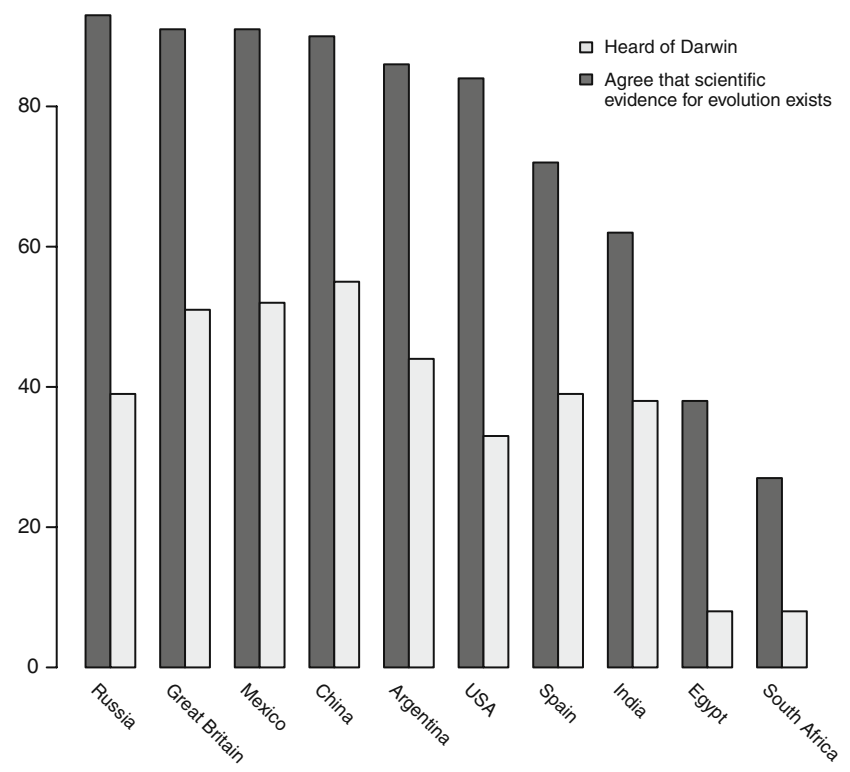

Fig. 2 Familiarity with Darwin and acceptance of evolution in ten countries. (Data from Rogers 2009) 


\section{Student Views on Evolution and Creationism}

Although there are several research findings about high school teachers' beliefs and attitudes about evolution and creationism (discussed below), there are almost no corresponding data for high school students. So we will try to form some rough ideas about high school students' beliefs and attitudes by looking at what is known about college students. Such extrapolation should be treated with lots of caution - college students are, clearly, not perfectly representative of high school students - but presently it's the only large-scale representative alternative that we have.

More than 20 years ago, Harrold and Eve (1987) published a compilation that contained a report of a survey on attitudes toward evolution. Their data were drawn from university students in Texas $(n=443)$, Connecticut $(n=169)$, and California $(n=367)$, allowing some rough comparisons across three regions. All students were asked whether they agreed with the statement that "the theory of evolution correctly explains the history of life on Earth." Rejection of evolution was greatest among Texas students, who rejected evolution at about the same rate as is commonly seen over the decades among general samples of the American public. California students were considerably more likely to support evolution (only about $25 \%$ rejected it), and Connecticut students had the greatest proportion "unsure" (with about $20 \%$ expressing outright rejection). ${ }^{3}$

In the Texas university studied earlier, things haven't changed much. The first author has collected more than 400 completed survey instruments from several classes between 2005 and 2008 (partly discussed in Eve and Brown 2007). ${ }^{4}$ The percentage of students agreeing that "Human beings as we know them today developed from earlier species of animals" stood at $46 \%$, a figure almost identical to the one obtained in the Texas sample in 1987.

In a 2007 Florida sample of 665 third- and fourth-year college students majoring in education, using three separate questions, Losh and Nzekwe (2010) found that 43\% agreed that humans developed from earlier species of animals. Thirty-two percent agreed that an "intelligent designer" created humanity, and 35\% agreed that "God created humanity pretty much in its present form within the last 10,000 years or so."

\footnotetext{
${ }^{3}$ Rejection of evolution was not without vigor outside of the South (Texas is generally considered part of the South in such analyses), although belief in creationism has been shown to be higher generally in the so-called Deep South states of Alabama, Georgia, Louisiana, Mississippi, and South Carolina.

${ }^{4}$ As in the original study, the respondents were predominantly social science and liberal arts majors, but with considerable numbers of other majors represented.
}

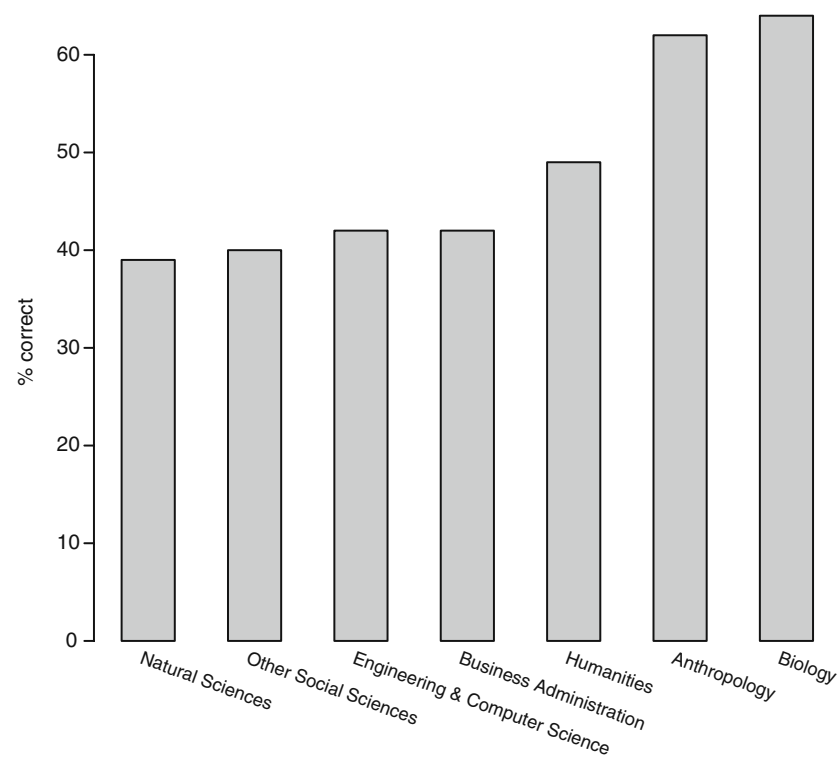

Fig. 3 Percentage of students agreeing that "Human beings as we know them today developed from earlier species of animals," by major. (Unpublished data from the first author, partly reported in Eve and Brown 2007)

Barnes et al. (2009) surveyed 591 students at three US colleges. Although most believed the earth was at least 4.5 billion years old, when presented with a question comparable to one from the Pew Research Center for the People and the Press (2009) survey, only 36\% favored "natural evolution." Twenty-two percent favored "guided evolution." Forty-two percent of the students chose a creationist response.

Aggregate data on college students can conceal important differences among them, such as those related to academic major. Data in Fig. 3 reflect the first author's polls of his students (see details of study above) arrayed by disciplinary major in response to the standard National Science Foundation science literacy item, "Human beings evolved from earlier species of animals" (National Science Board 2008). Anthropology majors did best on this question, even when compared to biology or physical science majors. Biology majors were a close second. However, majors in other sciences or engineering for the most part actually did not do well. ${ }^{5}$ Barnes et al. (2009) reported that $52 \%$ of science majors, $48 \%$ of social science majors, and $42 \%$ of non-science majors accepted completely natural evolution for all living things.

\footnotetext{
${ }^{5}$ It is tempting to hypothesize that some of these patterns may be due to differing proportions of majors based on such variables as nationality. The first author, for example, has taught an honors course in the history of science where he found many of his physical science students to be from nations dominated by non-Christian religions. Such an interpretation, however, remains pure speculation until further analyses are completed.
} 
Seventy-eight percent of Losh and Nzekwe's (2010) science education majors accepted evolution, as did $58 \%$ of psychology students and $54 \%$ of social studies education students, compared with only $28 \%$ of elementary education majors. Only $17 \%$ of future science educators agreed that God created humans in their present form, compared with $31 \%$ of elementary educators. On the other hand, more than $60 \%$ of all education majors (including science education) agreed that God guided human evolution.

\section{Why Do People Reject Evolution?}

Benassi et al. (1980) offered a typology of sources for pseudoscientific beliefs:

(a) Common errors in human reasoning

(b) Poor or erroneous science education

(c) Sensationalistic or inadequate media coverage of science topics

(d) Sociocultural factors (e.g., nationality, religious affiliation, and socialization specific to one's race or gender)

We will briefly discuss each of these in the context of belief in creationism.

\section{Common Errors in Human Reasoning}

Considerable research by heuristics scholars (see research cited in Losh 2003) and cognitive psychologists elaborates some of the errors in "intuitive" reasoning that make it harder for people to understand and accept evolution. For example, pastors, attorneys, and journalists often "prove" their points by enthusiastically citing evidence selectively and using anecdotal stories and appeals to authority as "evidence" to support already accepted theses. Laypersons tend to find these direct arguments more persuasive than the more indirect and circuitous - if more reliable - methods scientists use to test hypotheses.

Furthermore, beliefs and attitudes about evolution are embedded in already existing mental schema that encompass thoughts about science more generally, education, familial loyalty, or religion, and the nature of these schema affects how even the best science teaching is received. If, for example, elementary school pupils receive a mix of "Bible science" and science museum demonstrations in their science classes, they will tend to try to assimilate incoming information in middle and high school into their already-formed knowledge and attitudes. Highly discrepant information tends to be rejected. Without extensive cognitive "restructuring" of both existing and new information, the original mental structures tend to persist (e.g., see several chapters in Driscoll 2005).

\section{Poor or Erroneous Science Education}

It is often assumed that high school students and college graduates who accept creationism suffer from a lack of instruction on the topic or at least from poor basic science teaching. However, there is another, often overlooked, possibility: that students' own teachers may not accept evolution as valid, and thus be inclined to present creationism or to present evolution as invalid. Reactions by others to this hypothesis sometimes claimed that such an explanation was simply absurd. However, subsequent research indicates that this is, indeed, a not infrequent problem.

Perhaps the earliest US study to systematically examine pseudoscience beliefs among teachers was Eve and Dunn (1990), which drew a random national sample of high school biology teachers recruited through the National Science Teachers Association. ${ }^{6}$ When respondents were asked to assess "God created humanity pretty much in its present form within the last 10,000 years or so," $14 \%$ replied "definitely true," $10 \%$ "probably true," $45 \%$ "definitely false," and 19\% "probably false." A further 10\% replied that there was "inconclusive evidence," while yet another one half percent replied, "never heard of it." Not quite half of the teachers were prepared to fully reject strict creationism. (Interestingly, when asked if humans and dinosaurs existed at the same time, $19 \%$ agreed either "definitely" or "probably.")

More recently, Berkman et al. (2008) surveyed a national sample of 939 high school biology teachers (with a response rate of $48 \%$ ). When asked whether "Human beings have developed over millions of years, but God had no part in this," 28\% agreed. When asked whether "Human beings have developed over millions of years, but God guided this process," 47\% agreed. When asked whether "God created human beings pretty much in their present form within the last 10,000 years or so," $16 \%$ of these teachers agreed.

Moreover, those opinions were often voiced in the classroom. In the survey of Berkman et al., 25\% of teachers indicated that they devoted at least one or two classroom hours to creationism; nearly half of that $25 \%$ indicated that they present creationism as a "valid scientific alternative to Darwinian explanations for the origin of species," and nearly half of that $25 \%$ indicated that they emphasize that "many reputable scientists" view creationism as a valid alternative to evolution. Similarly, in their survey of 665 future teachers, Losh and Nzekwe (2010) found that although $83 \%$ reported that they had been taught about evolution in high school, $40 \%$ of that number was taught

\footnotetext{
${ }^{6}$ The survey was sent to 387 teachers, sampled from a larger sample drawn from a data tape of nearly 20,000 secondary school biology and life science teachers provided by the National Science Teachers Association in Washington, DC. A response rate of $49 \%$ was obtained through mailed surveys. The sample size was small because funding sources regarded the topic as too hot to handle.
} 
creationism alongside, meaning one third of these future teachers were taught creationism sometime during high school.

The problem is not just at the level of high school instruction. For many historic reasons, elementary school educators in most states teach all academic subjects. Although they rarely teach evolution, these instructors often present units on earth science and elementary biology. In Losh and Nzekwe's survey (2010), only $28 \%$ of 305 elementary education majors accepted "natural evolution." More than $60 \%$ endorsed variants of intelligent design and $31 \%$ subscribed to young-earth creationism. Assuming that the prevalence of creationist belief among elementary school educators is comparable to that of the elementary education majors surveyed by Losh and Nzekwe (2010), it is likely that many of them are teaching creationist ideas or at least downplaying or omitting evolutionary ideas in their classrooms. As a result, their students are deprived of the scaffold, as learning sciences scholars would call it, that would make it easier for them to learn about evolution in later grades.

The good news in the data of Berkman et al. is that a far smaller percentage of biology and life science teachers are creationists than is the case for the general public. Creationists were also few among Losh and Nzekwe's future science teachers. There's more good news: in Eve and Dunn's (1990) sample, at least $25 \%$ of teachers were creationists, whereas the sample of Berkman et al. (2008) showed only $16 \%$. However, although this seems an improvement, roughly one in six current high school biology teachers self-identifies as a creationist. Apparently, there is a degree of self-imposed restraint because only about one in eight admitted actually teaching creationism.

It seems likely that most of the problem concerning teachers who reject evolution occurs almost exclusively at the K-12 level of education. It is especially an issue at the high school level when evolution is first likely to be taught (although a recent case drawing national attention took place at the middle school level: Anonymous 2008). ${ }^{7}$ Except in Bible colleges, very few college science faculty endorse or teach creationism, and the overwhelming majority of college biology and life science instructors teach evolution when the topic of origins arises. Eve and Belhadi (2008) sampled Texas higher education faculty who had recently taught human evolution. Four hundred sixty-four completed surveys (a response rate of more than $45 \%)$. At most, about $2 \%$ showed any sympathy for creationism. Moreover, of this $2 \%$, most had not actually taught their own classes in evolution; none were senior faculty at prestigious institutions. It seems safe to assume

\footnotetext{
${ }^{7}$ Apparently, the middle school teacher also burned crosses in the arms of selected students.
}

that if so little support for creationism exists among Texas college and university faculty, it's likely to be lower in nearly all other states, reemphasizing the fact that the real battleground is in the K-12 system. Currently, $40 \%$ of American adults have any college degree, including a twoyear Associate of Arts degree. Thus, most US adults receive their final formal life sciences education in middle or high school. For many Americans, high school is the final battleground for the evolution wars.

Erroneous or Sensationalist "Media Science" and the "Shadow Culture"

Turning to the third source of pseudoscientific belief from Benassi et al. (1980), sensationalistic or inadequate media coverage of science topics, media coverage of science has blossomed in quantity in the past several decades, although not consistently through all media. It is perhaps a golden age for popular books about science, with marvelous books by the likes of Richard Dawkins, Carl Zimmer, Jerry Coyne, Neil Shubin, and Sean B. Carroll (to name only authors on evolutionary topics) on the shelves. The diversification of television from broadcast only to cable has resulted in the proliferation of channels devoted to science topics. Coverage of science in newspapers and magazines, at its height in the 1970s and 1980s, is suffering now, due to general problems with the publishing industry. Taking up the slack is the Internet, with its burgeoning number of websites and blogs devoted to defending science and debunking pseudoscience. At the same time, though, these same trends are also reflected in conservative religious circles, which have developed a prolific media culture of films, journals, books, websites, and "research centers" that shadows mainstream media.

The effect of this increase in media science coverage is good in part. In a presentation at a session of the American Association for the Advancement of Science, Jon Miller, a well-known expert on science literacy, noted that in recent years, US adults have become more scientifically literate. His analysis (Miller 2007) indicates that much of the improvement seems to have occurred among those who have taken at least one college science course. ${ }^{8}$ Apparently, sensitization to science during one's formal education facilitates lifelong learning about science through selfeducation. Presumably, this occurs through self-directed study utilizing increased access to science through the increase in mass market science publications and online information about science.

\footnotetext{
$\overline{{ }^{8} \text { Losh (2010) }}$ has argued that the noted improvement in US adult science literacy is also due to high school science classes. The debate continues, but the important point remains that science courses in formal education somehow lead to lifelong self-education in science topics.
} 
However, disturbing countertrends exist. Many "science" shows now appear on television channels such as the Discovery Channel and the Science Channel. Although the shows are usually presented as scientifically accurate, a substantial proportion flirt with, or even fully embrace, pseudoscientific content - presumably to titillate viewers and bolster ratings. Similarly, the producers of television and radio talk shows fully understand that controversy sells much better than harmony. How many viewers or listeners will be excited by a show presenting a bunch of scientists amicably agreeing about global warming? Instead, producers search for the rare global warming or evolution scientist denier, juxtaposing them with someone holding the opposite viewpoint. The viewer is left with the impression that the scientific community is deeply divided on the "controversial" topic even when only a very few proponents back one of the viewpoints.

There are also, of course, creationist groups who specifically produce media products promoting creationism as valid science. For many years the Institute for Creation Research (ICR) was the premier such organization, well known for its printed tract series "Acts and Facts." The ICR has been supplanted, however, by Answers in Genesis (AiG), which produces a much more extensive line of media productions - books, videos, internet sites, and so on - promoting creationism. AiG has also established a procreationism museum, just south of Cincinnati, with very slick production values, a well-oiled publicity machine, and substantial attendance, at a reported cost of 27 million dollars (Eve 2009).

Joining the young-earth creationist groups in producing a shadow media culture aimed at promoting creationism is the Discovery Institute, the de facto institutional headquarters of intelligent design - the strategy of promoting creationism in general without being committed to any specifics about the age of the earth, the identity of the designer, and so forth (Forrest and Gross 2007). Much of the Discovery Institute's activities are aimed at producing books, videos, and media that promote creationism. It was reported in 2001 that the Discovery Institute's Center for Science and Culture had produced 25 books, a stream of conferences, and more than 100 doctoral and postdoctoral fellowships in just its first five years (Willoughby 2001) and it has not been idle in the years since, issuing a steady stream of books, articles, press release, blog posts, podcasts, and videos. The Discovery Institute is also impelled to complain about what it deems to be misleading media coverage of evolution and of intelligent design: its Evolution News \& Views blog proclaims that "[t]he misreporting of the evolution issue is one key reason for this site."

Interestingly, the young-earth creationists and the intelligent design proponents were both happy to join forces in publicizing a recent film that ran nationally in commercial movie houses, i.e., the movie Expelled: No Intelligence Allowed, promoted by conservative pundit Ben Stein. The film derives its title from its central contention that many well-known scholars who actually support creationism are afraid to speak out of fear of being expelled from the academy. Consult the National Center for Science Education's website "Expelled Exposed" (http://www.expelledex posed.com/) for a thorough debunking of this film's misleading claims about evolution, intelligent design, and the supposed persecution of proponents of intelligent design. It is notable, however, as a prime example of how the shadow media culture of creationism can make inroads in the general media culture-Expelled premiered in more than 1,000 theaters nationwide, even though in the end it seems to have lost money for its producers.

\section{Sociocultural Factors}

The fourth source of pseudoscientific belief from Benassi et al. was labeled "sociocultural factors," which are defined as unrelated to individual psychological inadequacy or cognitive deviance. In the present case, it is clear that positions on creationism and evolution are highly correlated with a host of sociological factors such as religious affiliation, region of residence, and political outlook. It is no surprise that in the general public, Christian religiosity is strongly correlated with disbelief in evolution (Mazur 2005). In their survey of education majors, Losh and Nzekwe (2010) found that the best predictor of attitudes toward evolution and creationism was self-described importance of religion (controlling for religious denomination, basic science literacy, and several demographic variables). Similarly, in their survey of college students, Barnes et al. (2009) found "the two factors most strongly related to belief in the creation of all living things were religiosity and literalness."

Although the general public is interested in "new scientific discoveries" (by which they largely mean medical advances; National Science Board 2008), it is seldom intensely passionate about science topics. Typical citizens don't usually engage in white-hot arguments or bar fights over whether or not atoms exist or whether continents actually drift. So the very passion characterizing the creationism versus evolution debate is a clear clue to a social or behavioral scientist that a lot more is going on than a mere discussion about what is good scientific evidence or procedure.

Students of social movements find it easy to show correlations among white evangelical Christians between social movement adherents' opinions about the age of mankind on the one hand with their stance on social movement issues such as gay rights, legal abortion, women's equality, and so on the other (see, e.g., Eve and 
Harrold 1991). This may strike the casual observer as very curious: for example, why should one's opinion about the age of the Earth or humankind's origins correlate with their attitudes about homosexuality?

During a nationwide panic in the mid-1980s over an alleged huge underground satanist cabal (Victor 1993), a rumor circulated in a small town southwest of Dallas that blonde, blue-eyed high school students would be waylaid and sacrificed by satanists on Halloween eve (for a detailed analysis of the event, see Roy et al. 1996). A huge meeting of parents was organized to allay this imminent tragedy. When one organizer of the meeting was later interviewed by the first author, she was asked whether she felt that the United States was imperiled by certain "social problems," such as homosexuality, drug abuse, prostitution, or abortion. Among these was "the teaching of evolution in the public school classroom." After evolution was mentioned, the organizer paused for a bit and then replied, "That's the cause of all the others, isn't it!" The organizer was a Biblical inerrantist who found the following reasoning to be plausible. If the Bible gets the age of the earth wrong, it might be wrong about many other things - maybe all other things. Her fear was that accepting evolution is the first step down a slippery slope to secular humanism or worse. It is also an example of how evolution information can be embedded in complex schemas.

Conservative Christians often describe secular humanism as "setting mankind above God"- - by which they mean humans decide about what is moral, not God as He reveals himself through Scripture. Indeed, public opinion polls have consistently shown religious conservatives hold very dark views about human nature, viewing it as inherently sinful and dangerous, thus in need of coercive external control (Adorno et al. 1950; Lipset 1960). Biblical inerrantists tend to believe that if humans are allowed to make decisions about morals, they will make poor ones, leading to a host of social problems - drug use, homosexuality, prostitution, and so on - and to consequences in the afterlife. So it's not really the actual age of the Earth, or the science associated with determining it, that upsets such persons, it's this progression from questioning the age of the Earth or the origins of humanity to immorality or even genocide (as alleged in the film Expelled), and to eternal torment in Hell, that is the real source of concern.

The insight garnered from the above experience leads us to hypothesize that much of the creationism versus evolution debate actually arises from the fact that people in the United States today form aggregates that rely on different ways of testing proffered "truth claims"-including those about the age of humankind (e.g., see Losh 2003). One attitude toward ways of testing truth claims can be called cultural traditionalism, which allows appeals to tradition, faith, authority, scripture, and revelation as the means for assessing a given truth claim. The confidence exuded by those promulgating such rules can ease anxiety and disorientation in an age of rapid cultural and economic change. In a popular catchphrase, "God said it, I believe it, that settles it!"

A second common set of attitudes toward ways of testing truth claims can be called cultural modernism. These rules follow guidelines put forward by Enlightenment thinkers, which demand that any claim about phenomena in the natural world should be evaluated by using empirical data to test hypotheses. If the hypothesis is confirmed, it is regarded as true, but always tentatively, subject to revision in the light of further evidence and theory. Much of the current controversy over evolution arises out of conflict between these two fundamentally different attitudes toward ways of knowing.

\section{Implications for the Teaching of Evolution in the Science Classroom}

It is uncontroversial that in order to teach evolution effectively, it is necessary to present students with good scientific data. Using basic science facts typically taught in late elementary school and reviewed in middle school (National Science Board 2008: Table 7-5; Pew Research Center for the People and the Press 2009), Losh and Nzekwe (2010) found that higher basic science literacy among education majors predicted acceptance of evolution and rejection of strict creationism. Similarly, in Eve's Texas university classroom samples, there was a highly significant Pearson's correlation of $0.43(p<.0001)$ between basic knowledge and evolution support.

But it's not enough. The common assumption that having students master theory and data about evolution will, of itself, change their minds is simply wrong in many cases. Archaeologist Francis B. Harrold reports that a student who passed a test on human evolution wrote at the bottom of it, "Of course, I don't believe any of this. I believe in the Bible." An apparent student mastery of evolution in the classroom may be instead just playing the game in pursuit of a good grade. For another piece of anecdotal evidence, the first author once watched wellknown skeptic Michael Shermer debate a conservative Christian about whether humans invented God, or vice versa. Hundreds of intensely interested students attended. Shermer asked this crowd, "If I could definitely prove to you one way or another tonight that the facts support the position contrary to your own, how many of you would be willing to change your mind?" About ten people raised their hands.

Moreover, there is the question of permanency. Collegelevel instructor Thomas Gray (1987) taught a "debunking 
class" focusing on several pseudoscience areas. Although belief in such claims was markedly lower at the end of a semester, when Gray retested his students one year later, their beliefs had overwhelmingly reverted to the same level as in a pretest at the beginning of his course.

Why should such a result occur? One possibility is the game-playing factor just mentioned. It's also possible that students abandoned what they had learned in the course as time passed. As noted earlier, restructuring is typically necessary to admit new theory and facts into cognitive schema; without it, lasting change is unlikely to occur. This latter proposal, in turn, leads to two other possibilities. One is that students may have simply forgotten how to think critically - or never learned how in the first place. The second, and we suspect the more likely possibility, is that the social control network of friends, parents, coworkers, etc., continued to reinforce the same beliefs that students held upon entering Gray's class. This last possibility would be consistent with many studies about attitude formation and retention in the social psychology literature. If so, then any attempt to teach controversial scientific topics will need to be designed in light of this body of findings.

In light of the foregoing discussion, it is clear that it is necessary to take account of the four factors identified by Benassi et al. (1980). If we hope for evolution to be taught effectively, we must realize that there are tendencies native to human reasoning that make evolution hard to understand and accept; that teachers are often unequipped or unwilling to present evolution properly; that there are media sources that are, intentionally or inadvertently, fostering misconceptions about evolution in the general public; and that there are powerful social institutions that are working to instill and reinforce rejection of evolution in favor of various forms of creationism. There already is substantial pedagogical literature that discusses ways of teaching in light of these factors (e.g., Alters and Alters 2001; Meadows 2009; Nelson 2000), which deserves to be further expanded, researched, and (most important of all) applied.

\section{Broader Considerations}

Beyond instructors learning to teach evolution more effectively in their individual classrooms, what can be done to counteract the factors that promote and reinforce the rejection of evolution? The place to start is with reform of the educational system, and the challenge is the decentralized nature of education in the United States. In contrast to most of Europe, where curriculum is generally established at the national level, the US educational system was largely founded on the politico-legal principle of "local control.", Individual states set their own standards for what will be taught in the public school science classroom-sometimes explicitly compromising the treatment of evolution to placate creationists, as in Kansas in 2005 or in Texas in 2009. Decisions about textbooks are sometimes also made at the state level. As for curriculum and instruction, they are even further under local control, with individual school districts — of which there are more than 15,000 - enjoying considerable autonomy.

What all this means is that in the United States, supporters of evolution education must be prepared to become involved in defending evolution against attempts to compromise it at all levels, from individual classrooms to local schools and districts to state boards of education and legislatures. It's likely that a highly effective way to try to combat creationism, at least in the short term, is to influence the episodic deliberations that decide the content and textbooks to be used in public school science classrooms. And to do so, it's helpful to recruit-or organize-social movement organizations to channel and focus the energy of activists. The National Center for Science Education, under the leadership of its executive director Eugenie C. Scott, has been primus inter pares of the social movement organizations working to defend the teaching of evolution; counterparts at the state level include Texas Citizens for Science and Kansas Citizens for Science. And social movement organizations with broader concerns, such as the Americans United for Separation of Church and State or the Texas Freedom Network, have also deemed the defense of evolution to be within their missions.

To date, however, the creationism movement has been better organized, funded, and motivated than its countermovement. (Familiarity alone can make creationist tenets more attractive to unsophisticated laypersons.) And its efforts have been relentless. In 2005, the National Center for Science Education recorded more than 80 controversies in 30 states over evolution, primarily concerning the place of evolution-and supposed alternatives to it such as creation science and intelligent design -in the public school science curriculum (Branch 2006). Louisiana and Texas recently enacted policies - a law in Louisiana's case, a revised set of state science standards in Texas's caseimplicitly encouraging challenges to evolution (linked with global warming perhaps to sidestep Establishment Clause

\footnotetext{
${ }^{9}$ This very same tradition makes it more common to encounter the influence of "lay" ministers in such regions - meaning those whose main qualifications are often consist of having been "called by the Lord to minister to the flock." In most of Europe, the clergy is much more likely to be the product of a seminary - and therefore to have been required to be much more highly educated in general.
} 
issues; Kaufman 2010). And there is no prospect of such efforts ending.

Triumphing in the deliberations that decide the content and textbooks to be used in public school science classrooms will not be sufficient, however, for what teachers do behind their closed classroom doors may not comply with those decisions. For example, Bandoli (2008) suggests that there is little evidence that the differing coverage of evolution in the Indiana and Ohio science standards is manifested in the quality of evolution instruction in those states. And Berkman et al. (2008) report that some instructors teach creationism despite the Edwards decision and scant evolution despite its presence in textbooks and standards. Consequently, it behooves parents to monitor good science teaching. Many conservative Christians show no reluctance to exert pressures on teachers to include creationism in or exclude evolution from their classrooms; unfortunately, that may mean that those in favor of evolution cannot afford not to try to influence public education.

In the long run, what will be required will be better and more teaching of evolution at the college level, higher standards for knowledge of pre-service teachers, and higher standards for employment of in-service teachers. As Berkman et al. (2008) comment, "Scientists concerned about the quality of evolution instruction might have a bigger impact in the classroom by focusing on the certification standards for high school biology teachers. Our study suggests that requiring all teachers to complete a course in evolutionary biology would have a substantial impact on the emphasis on evolution and its centrality in high school biology courses. In the long run, the impact of such a change could have a more far reaching effect than the victories in courts and in state governments." Implementing such reforms will be a long, complicated, and messy process, and the support of social movement organizations will be needed here, too. Thus, in both the short term and the long term, teachers, parents, and others who wish to counter the influence of advocates for creationism will need to learn to create social movement organizations, provide resources for the health of such movements, and solve problems of member recruitment and commitment. Among other factors discussed above, any viable solution to the problem of creationism in public schools must be met with better political organization and activity than seen up until now. It may be encouraging to recall the famous words of Margaret Mead: "A small group of thoughtful people could change the world. Indeed, it's the only thing that ever has."

Acknowledgements The first author wishes to acknowledge the assistance of his research assistant Paul Blankenship, in gathering some of the information about the range and effectiveness of attempts at instruction in evolution.

\section{References}

Adorno TW, Frenkel-Brunswick E, Levinson DJ, Sanford RN. The authoritarian personality. New York: Harper and Brothers; 1950.

Alters BJ, Alters SM. Defending evolution: a guide to the evolution/ creation controversy. Sudbury, MA: Jones and Bartlett; 2001.

Anonymous. Town split over teacher accused of preaching. Associated Press, July 8, 2008. Available at: http://www.msnbc.msn.com/id/ 25585916/ (retrieved March 1, 2010).

Bandoli JH. Do state science standards matter? Comparing student perceptions of the coverage of evolution in Indiana \& Ohio public high schools. Am Biol Teach. 2008;70(4):212-6.

Barnes RM, Keilholtz LE, Alberstadt AL. Creationism and evolution beliefs among college students. Skeptic. 2009;14(3):13-6.

Benassi VA, Singer BF, Reynolds C. Occult belief: seeing is believing. J Sci Study Relig. 1980;19:337-49.

Berkman MB, Pacheco JS, Plutzer E. Evolution and creationism in America's classrooms: a national portrait. PLoS Biol. 2008;6(5): e124.

Bishop G. Polls apart on human origins. Public Opinion Pros; 2006. Available at: http://www.publicopinionpros.norc.org/features/ 2006/aug/bishop.asp (accessed March 31, 2010).

Branch G. Defending the teaching of evolution: strategies and tactics for activists. In: Scott EC, Branch G, editors. Not in our schools: why intelligent design is wrong for our schools. Boston: Beacon Press; 2006. p. 130-52.

Branch G. Creationism as a global phenomenon. In: Robbins RH, Cohen MN, editors. Darwin and the Bible: the cultural confrontation. Boston: Pearson Education; 2008. p. 137-51.

Coleman S, Carlin L, editors. The cultures of creationism: antievolutionism in English-speaking countries. Aldershot, UK: Ashgate; 2004.

Driscoll MP. Psychology of learning for instruction. 3rd ed. New York: Pearson Education; 2005.

Eve RA. Reflections on a visit to the Creation Museum. Reports of the National Center for Science Education. 2009;29(5):31-3.

Eve RA, Belhadi C. Evolution, creationism, and the public schools. Austin, TX: Texas Freedom Network Education Fund; 2008.

Eve RA, Brown MK. Demographic, social, and attitudinal correlates of scientific literacy in a sample of college students. Paper presented at the National Social Science Association Annual Meetings, Las Vegas, April 2007.

Eve RA, Dunn D. Psychic powers, astrology, and creationism in the classroom? Am Biol Teach. 1990;52(1):10-21.

Eve RA, Harrold FB. The creationist movement in modern America. Boston: Twayne; 1991.

Forrest B, Gross PR. Creationism's Trojan horse: the wedge of intelligent design, rev. ed. New York: Oxford University Press; 2007.

Gray T. Educational experience and belief in the paranormal. In: Harrold FB, Eve RA, editors. Cult archaeology and creationism: understanding pseudoscientific beliefs about the past. Iowa City, IA: University of Iowa Press; 1987. p. 21-33.

Greenfield KT. The autism debate: who's afraid of Jenny McCarthy? Time, February 25, 2010. Available at: http:/www.time.com/ time/nation/article/0,8599,1967796,00.html (retrieved February 27, 2010).

Harrold FB, Eve RA, editors. Cult archaeology and creationism: understanding pseudoscientific beliefs about the past. Iowa City, IA: University of Iowa Press; 1987.

Kaufman L. Darwin foes add warming to targets. The New York Times, March 3, 2010. Available at: http://www.nytimes.com/2010/03/04/ science/earth/04climate.html (retrieved March 6, 2010).

Lipset SM. Political man: the social bases of politics. Garden City, NY: Doubleday \& Company; 1960. 
Losh SC. On the application of social cognition and social location to creating causal structures. Educ Res Q. 2003;26(3):17-33.

Losh SC. Age, generational, and educational effects on American adult public understanding of science. In: Bauer MW, Shukla R, Allum N, editors. The culture of science: how does the public relate to science across the globe? New York: Routledge; 2010. in press.

Losh SC, Nzekwe B. Creatures in the classroom: attitudes and beliefs about fantastic beasts, extraterrestrials, and creationism among education majors. Paper presented at the American Association for Public Opinion Research meetings, Chicago, May 2010.

Mazur A. Believers and disbelievers in evolution. Polit Life Sci. 2005;3(2):55-61.

Meadows L. The missing link: an inquiry approach for teaching all students about evolution. Portsmouth, NH: Heinemann; 2009.

Miller JD. The impact of college science courses for non-science majors on adult science literacy. Paper presented to a symposium entitled "The Critical Role of College Science Courses for NonMajors" at the annual meeting of the American Association for the Advancement of Science, San Francisco, February 2007.

Miller JD, Scott EC, Okamoto S. Public acceptance of evolution. Science. 2006;313(11):765-6.

National Science Board. Science and engineering indicators 2008. Arlington, VA: National Science Foundation; 2008.

Nelson C. Effective strategies for teaching evolution and other controversial topics. In: Skehan J, Nelson C, editors. The creation controversy and the science classroom. Arlington, VA: National Science Teachers Association Press; 2000. p. 19-50.
Newport F. Majority of Republicans doubt theory of evolution. Gallup, June 11, 2007. Available at: http://www.gallup.com/ poll/27847/Majority-Republicans-Doubt-Theory-Evolution.aspx (retrieved February 28, 2009).

Pennock RT. Should creationism be taught in the public schools? Sci Educ. 2002;11(2):111-33.

Pennock RT. Creationism and intelligent design. Annu Rev Genom Hum Gen. 2003;4:143-63.

Pew Research Center for the People and the Press. Public praises science; scientists fault public media. Washington DC: Pew Research Center; 2009. Available at: http://people-press.org/ reports/pdf/528.pdf (retrieved February 28, 2010).

Rogers S. God or Darwin? The world in evolution beliefs. The Guardian, July 1, 2009. Available at: http://www.guardian.co.uk/ news/datablog/2009/jul/01/evolution (retrieved February 28, 2010).

Roy L, Eve RA, Shupe A. Satan will get you if you don't watch out [part 1]. The skeptic: the newsletter of the North Texas Skeptics 1996 (January):10(1). Available at: http://www.ntskeptics.org/ 1996/1996january/january1996.htm\#satan (retrieved March 5, 2010).

Specter M. Denialism. New York: Penguin; 2009.

Victor JS. Satanic panic: the creation of a contemporary legend. Chicago: Open Court; 1993.

Willoughby KL. Discovery Institute emerging as force in creation, public policy. Baptist Press, May 15, 2001. Available at: http:// www.baptist2baptist.net/b2barticle.asp?ID=147 (retrieved March 7, 2010). 